\title{
Book reviews
}

NEUROLOGY OF EAR, NOSE AND THROAT DISEASES By Charles H. Edwards. (Pp. 305; £6.) Butterworths: London. 1973.

I have enjoyed reading this little book. It is always rewarding to learn from a colleague who has made a special study of a branch of neurology in which one feels ignorant. But it is infuriating to find major deficiencies in exactly those areas where it is useful to have a book at one's elbow. Surely one would expect to find, in a book with this title, detailed information about audiometry and loudness recruitment in neurological diagnosis. Bell's palsy is doubtfully otological, but at least one should find the best of electrodiagnostic work referred to and some guidance on the indications for surgery. Are any of the widely marketed drugs of proven value in Ménière's disease? I still do not know. This book could be so valuable. Perhaps a new edition would fill the gaps and give a better bibliography and index.

J. A. SIMPSON

ADVANCES IN OTO-RHINO LARYNGOLOGY: CURRENT STUdies in otoneUrology. Edited by C. R. Pfaltz, H. O. Barber, and J. M. Fredrickson. (Pp. 376; illustrated; FR. 19.55.) Karger: Basle. 1973.

With this volume 19 in the series Advances in OtoRhino Laryngology are published the papers delivered at the meeting of the Barany Society, held in Toronto in August 1971.

There are 35 contributions from over 80 authors, mostly from North America and Europe, devoted to current researches in otoneurology and allied sciences, covering laboratory and clinical aspects. The address of the guest of honour, Dr. G. von Békésy, is a scholarly monograph entitled 'Sense organs and their sensitivity' in which he discusses the difficulties and pitfalls in making biological threshold measurements of sensory perception in living organisms. The remainder of the articles cater for a wide field of interest and the organizers are to be congratulated on the range of topics selected for presentation. These are classified under section headings entitled anatomy, experiments on peripheral receptors, vestibular neurophysiology, neurochemistry, central vestibular system, nystagmus instrumentation, vestibular studies in normal humans, and clinical studies.

The volume is well produced, in spite of a curious mixture of qualities of paper and the printers have excelled in the reproduction of figures and the quality of the photographs.

Otoneurology is now well established as a specialty in many hospitals, institutes, and universities and with the regular occurrence of teaching courses, symposia and meetings devoted to it, together with their relevant publications, it can fairly be said to have come of age.

NEIL T. BRATTEN

E.E.G. OF HUMAN SLEEP: CLINICAL APPLICATIONS By

R. L. Williams, I. Karacan, and C. J. Hursch. (Pp. 169; illustrated; £8.) Wiley: Chichester. 1974. This book achieves all the aims envisaged by the authors in the introduction-in particular, to serve as an atlas of the electroencephalogram of human sleep for the clinician. It traces the history of human sleep research and briefly presents the current EEG methods used in this field. The major section of the book represents the results of an intensive 10 year study by the authors of normal human sleep patterns of age and sex matched subjects between the ages of 3 and 79 years. The results are discussed extensively in addition to being presented graphically and in tabular form. Relevant examples of EEG and EOG tracings are also illustrated. The chapter on clinical sleep disorders presents a practical review of the literature on this subject.

This book is exceptionally readable and, while concise, it remains informative. It must be regarded as invaluable as a basic reference atlas on human sleep, not only to those directly involved in sleep research, but to all clinicians.

ANNE P. MCGEORGE

SOMATOSENSORY SYSTEM. VOl. 2 Of HANDBOOK OF SENSORY PHYSIOLOGY Edited by A. Iggo. (Pp. 851; illustrated; DM. 262.) Springer: Berlin. 1973.

No investigation of disorders of motor function is now complete without quantitative studies by electrophysiology. Not least of the value is the elimination of the subjective element in the patient-doctor interchange. It would be a major advance for clinical neurology if objective techniques could be devised for assessment of sensation and its disorders. This has not yet been achieved, but the essential groundwork 
is being steadily carried out. Human studies on the thalamus and cortex are already well advanced and the ingenious gate-theory for pain has stimulated valuable therapeutic studies. This volume, one of a major new series, is a valuable record of present ideas. As the editor rightly observes, in an active research field it is both necessary and usual to find conflicts of ideas between different expert contributors. Doubtless many of the ideas in this book will be superseded but it is a good summary of current views on the somatosensory system.

J. A. SIMPSON

CURRENT TOPICS IN NEUROPATHOLOGY Edited by

K. Jellinger. (Pp. 241; illustrated; price not stated.) Facultas: Vienna. 1973.

This paper-bound volume of 241 pages contains 37 of the papers presented at the 4th Danube Symposium on Neuropathology which was held in May 1973. Papers were presented by East and West German, Polish, Rumanian, Swiss, Hungarian, American, and Austrian neuropathologists. Three of the main themes of the symposium-developmental abnormalities, inflammatory and viral diseases, and cerebral tumours and their experimental inductionhave been published. There is much of interest in all of the papers but many of them have appeared as formal publications in the European literature. Only two of the papers in this volume are in English. The majority of the others have English summaries which are either too short to convey more than the simplest outlines to the non-German or have completely lost their meaning in inaccurate translation. As an example, the English summary of Dr Dudka's paper on 'Primary, circumscribed melanomas of the nervous system' seems to be far from what he meant in respect of the established existence of melanin containing cells in some meningiomas and Schwannomas.

Most of the illustrations of macroscopical preparations, light and electron microscopy have printed well and adequately supplement the texts of some detailed papers on human malformations, such as corpus callosum agenesis, and holoprosencephaly.

This is the kind of volume that those neuropathologists who attended the conference would probably like to have, but for others it would probably be worthwhile browsing in a library copy. D. DOYLE

AROMATIC AMINo ACIDS IN THE BRAIN Produced by the CIBA Foundation. (Pp. 408; \$18.60.) Elsevier/Excerpta Medica/North-Holland: Amsterdam. 1974.

The aromatic amino acids are of special significance to brain function. Thus tryptophan is, for example, important in control of protein synthesis and in relation to formation of the biogenic amine serotonin. Changes in concentration of the aromatic amino acid or its derivatives occur in sleep and stress. It appears that the level of brain tryptophan is a key factor in affective disorders and possibly in schizophrenia, while serotonin is implicated in the biochemistry of headache. Well-recognized are the neurological effects of inborn errors of tryptophan, phenylalanine, and tyrosine metabolism. There was, therefore, good reason for the holding and publication of a CIBA Foundation symposium in May 1973, at which the basic biochemistry of brain aromatic amino acids was examined in depth. Each of the 20 articles by acknowledged experts begins with an abstract and the text of about 10 pages is usually followed by an edited discussion. The result is an excellent book in which the high scientific standard is matched by a clear attractive format. The book begins with a review of factors controlling plasma amino acid (especially tryptophan) concentration. This is followed by an account of amino acid transport in the brain. Their metabolism to a range of biogenic amines, as well as nutritional factors regulating levels of the amino acids and their derivatives, are reviewed.

Attention is particularly focused on the role of tryptophan and 5-hydroxytryptamine. The final part of the book deals with the topical question of tryptophan concentration and control of brain protein synthesis. Amino acid imbalance may competitively reduce availability of amino acids for synthesis or, as has been suggested, cause polysomal disaggregation. Recent information is given on these points and the use of analogues of phenylalanine and tryptophan is examined.

A. N. DAVISON

CEREBELLAR CORTEX, CYTOLOGY AND ORGANIZATION

By S. L. Palay and V. C. Palay. (Pp. 348; illustrated; \$64.) Springer: Berlin. 1974.

This book has been produced over many years with loving care not only by the authors but by the publishers, with thoroughness, attention to detail, and calm assessment of knowledge obtained to date. It is not hard to predict that it will become a classic, a joy to possess for those who like medical books and essential consultation for all those working on the anatomy and physiology of the cerebellar cortex.

All the cellular constituents are taken in turn, Purkinje cells, mossy fibres, basket and stellate cells, and many more, dealt with vividly by 'a little history' and then our knowledge brought up-to-date by electron micrographs of impeccable quality, or freeze-etch replicas and camera lucida drawings. 